\title{
The relationships of both transition shock, empathy, resilience and coping strategies with professional quality of life in newly graduated nurses
}

Xiaoyi Cao, Jin Li and Shu Gong*

\begin{abstract}
Background: Data on professional quality of life in newly graduated nurses are scarce. This study aimed to describe the levels of professional quality of life, and to explore the relationships of transition shock, empathy, resilience and coping strategies with professional quality of life in newly graduated nurses.

Methods: This was a cross-sectional study, which used a two-stage sampling method to recruit 393 newly graduated nurses in Sichuan province of China. Multiple regression analysis was used to explore the effects of transition shock, empathy, resilience and coping strategies on professional quality of life. Data were collected using standardized scales.

Results: The prevalence of average levels of compassion satisfaction, burnout and secondary traumatic stress in newly graduated nurses were 80.2, 38.2 and 57.5\%, respectively. Transition shock was a significant negative predictor, and empathy, resilience and adaptive coping were significant positive predictors for compassion satisfaction. Transition shock and passive coping were significant positive predictors, and empathy was a significant negative predictor for burnout and secondary traumatic stress. Resilience and adaptive coping contributed to burnout significantly and negatively.
\end{abstract}

Conclusion: Higher transition shock and lower empathy cause lower compassion satisfaction and higher compassion fatigue. More resilience and adaptive coping cause more compassion satisfaction and less burnout. More passive coping contributes to higher compassion fatigue. Strategies such as transition or preceptorship programmes, and empathy, resilience and coping training are effective methods to reduce transition shock, facilitate empathy, resilience and coping, and consequently, enhance professional quality of life in newly graduated nurses.

Keywords: Compassion fatigue, Compassion satisfaction, Coping strategies, Empathy, Newly graduated nurses, Professional quality of life, Resilience, Transition shock

\footnotetext{
*Correspondence: posteducation@126.com

Department of Nursing, West China Hospital/West China School of Nursing, Sichuan University, 37, Guoxue Road, Chengdu, Sichuan Province, People's Republic of China
}

C C The Author(s). 2021 Open Access This article is licensed under a Creative Commons Attribution 4.0 International License, which permits use, sharing, adaptation, distribution and reproduction in any medium or format, as long as you give appropriate credit to the original author(s) and the source, provide a link to the Creative Commons licence, and indicate if changes were made. The images or other third party material in this article are included in the article's Creative Commons licence, unless indicated otherwise in a credit line to the material. If material is not included in the article's Creative Commons licence and your intended use is not permitted by statutory regulation or exceeds the permitted use, you will need to obtain permission directly from the copyright holder. To view a copy of this licence, visit http://creativecommons.org/licenses/by/4.0/ The Creative Commons Public Domain Dedication waiver (http://creativecommons.org/publicdomain/zero/1.0/) applies to the data made available in this article, unless otherwise stated in a credit line to the data. 


\section{Background}

The nursing shortage receives global attention, which affects the quality of care. According to the latest data, the number of nurses worldwide is 20.7 million in 2013, and another 11.6 million nurses will be required in 2030 [1]. In China, although 4.1 million nurses are employed in 2018 [2], the nurses per 1000 inhabitants are 2.7, which are drastically lower than those in Western countries [3]. Therefore, it is essential to establish strategies for retaining experienced nurses and attracting newly graduated nurses (NGNs) to alleviate the ongoing nursing workplace crisis.

Professional quality of life represents cumulative positive (compassion satisfaction, CS) and negative experience (compassion fatigue, CF) caregivers perceive regarding their work as professional helpers [4], which affects the health and effectiveness of nurses. Recently, professional quality of life in nurses received much concern, especially for those employed in the emergency rooms, intensive care units and oncology wards [5]. Previous studies discovered that, higher CS and lower CF significantly contributed to higher job satisfaction, and lower anxiety, depression and turnover intention in experienced nurses [6,7]. As entry-level nurses, NGNs encountered great challenges in the transition to clinical practice, which resulted in high job stress, burnout and turnover intention [8]. Moreover, most existing studies explored the subjects of stress, job satisfaction, burnout and turnover, little attention was paid to professional quality of life in NGNs [6-8]. Thus, to examine the mechanism which affected professional quality of life in NGNs might contribute to developing strategies for facilitating $\mathrm{CS}$, alleviating $\mathrm{CF}$, and reducing turnover intention eventually.

Professional quality of life refers to the quality caregivers perceive as professional helpers, which incorporates CS and CF [4]. Of these, CS refers to the pleasure of a caregiver, which derives from being capable of engaging in work and dealing with costs of caring well. CF represents a caregiver's diminished capacity to care due to repeated exposure to the suffering of clients, which breaks into two parts: burnout and secondary traumatic stress (STS). The first part is associated with negative feelings of frustration and exhaustion related to difficulties in handling work effectively. The second part is associated with negative feelings triggered by work-related, secondary exposure to clients who suffer from traumatic events [4]. Recently, professional quality of life in nurses received widespread attention, which affected turnover, retention and their ability to provide care. Previous studies uncovered that, CS was less prevalent and CF was more prevalent in nurses with less years of job experience $[6,9,10]$. Another study found that, nurses with less than 3 years of experience reported lower CS and higher CF [11]. However, most existing studies explored professional quality of life and its related factors in experienced nurses, fewer studies examined these variables in NGNs with less years of job experience, who might perceive less CS and more CF in their transition to clinical practice.

The professional quality of life model was used to guide this study. Based on this model, positive (CS) or negative (CF) aspects of helping others can be affected by demographic, job-related and personal factors. Of those, demographic variables included age, gender, years of job experience and educational level; job-related variables included job stress, and support from managers and peers; and personal variables comprised personality, empathy and resilience [4]. Thus, according to the model, the following hypotheses were formulated: 1) as a job-related factor, transition shock resulting from poor adaptation to clinical practice was negatively and significantly associated with CS, and positively and significantly associated with CF in NGNs; and 2) as personal resources, empathy, resilience and coping strategies were significantly and positively associated with CS, and significantly and negatively associated with $\mathrm{CF}$, respectively.

NGNs usually experience considerable emotional burden during their transition to clinical practice [12]. To date, most existing studies focused on the description of transition experience in NGNs using qualitative studies. Meanwhile, some quantitative studies discovered a high prevalence of transition shock in NGNs despite differences in severity, and transition shock was a significant predictor for nurse turnover, job involvement, negative emotional states and adverse patient events [13]. However, no studies examined the relationship between transition shock and professional quality of life in this population.

Interestingly, regarding the association between empathy and professional quality of life in nurses, it was found that, empathy was the main etiology for CF [14]. Empathy was positively and significantly related to CS, but negatively and significantly related to $\mathrm{CF}$ among nurses in China and Portugal $[15,16]$. Furthermore, empathy was a significant contributor to CS in oncology nurses [17]. Therefore, although the significant associations between empathy and professional quality of life in experienced nurses were demonstrated across prior studies, no studies examined the correlation between empathy and professional quality of life in NGNs.

Resilience was a significant contributor to nurse turnover intention and work performance [18]. With regard to the relationship between resilience and professional quality of life in nurses, it was uncovered that, resilience was positively and significantly related to CS, but negatively and significantly related to CF in Australian nurses [19]. Higher resilience contributed to higher CS and lower CF significantly in Australian critical care nurses [20]. Accordingly, although there were consistencies in 
the associations between resilience and professional quality of life in experience nurses, little attention was paid to the relationships between these variables in NGNs.

Moreover, coping strategies affect nurse burnout, job satisfaction, turnover and retention. Regarding the associations between coping strategies and professional quality of life, a previous study on cancer nurses found that, passive coping was positively and significantly related to CF, but adaptive coping was not positively and significantly related to CS [17]. Another study on Australian critical care nurses revealed that, coping strategies had no significant effects on CS and CF, respectively [20]. Moreover, problem-solving coping significantly predicted CS, and avoidance coping significantly predicted CF among critical care nurses in Jordan [21]. Thus, inconsistent results existed in the correlations between coping strategies and professional quality of life in experienced nurses. Meanwhile, no studies explored whether and to which extent coping strategies affected professional quality of life in NGNs.

The aims of the study were to describe the levels of professional quality of life, and to examine the relationships of transition shock, empathy, resilience and coping strategies with professional quality of life in Chinese NGNs.

\section{Methods}

\section{Study design and setting}

This was a cross-sectional study conducted in Sichuan province, which is located in the southwest region of China. The formula of sample size calculation used in this study was $\left[n=\left(u_{\alpha} \sigma / \delta\right)^{2}\right]$. As no prior studies reported CS or CF in NGNs, the calculation of sample size was based on the scores of CS in the pilot study (mean = 37.69 , standard deviation $=5.02$ ). A minimal sample size of 387 was required based on the expected error of estimation of 0.5 and a $5 \%$ margin of error.

A two-stage sampling method was used. First, 10 tertiary hospitals in Sichuan province were selected (2 tertiary hospitals were chosen from eastern, southern, western, northern and middle regions of Sichuan province, respectively). Then, all of the NGNs in the selected hospitals were recruited. The NGNs meeting the following criteria were included: 1) having a nursing license; and 2) having job experience of no more than 1 year. The NGNs with maternity leave or sick leave during the survey were excluded. Finally, of 475 participants eligible, 393 participants voluntarily and successfully completed the survey with a response rate of $82.7 \%$.

\section{The study questionnaire}

Transition shock scale for newly graduated nurses assesses emotional reactions (e.g., doubt, confusion and disorientation) in NGNs due to the conflicting theories and realities in clinical practice. It comprises 33 items and 4 domains (physical shock, psychological shock, shock from knowledge and skills, and shock from organizational culture and climate). Each item is rated by a 5 -point Likert scale with higher scores indicating higher transition shock. The original Chinese scale indicates a satisfactory structural validity, and the Cronbach's $\alpha$ of each subscale ranges from 0.86 to 0.94 [22]. In this study, the Cronbach's $\alpha$ of each subscale ranged from 0.81 to 0.89 .

Jefferson Scale of Empathy appraises empathic qualities in providing care, which comprises 20 items and 3 subscales (standing in the patient's shoes, compassionate care and perspective taking). It is ranked by a 7-point Likert scale with higher scores indicating higher empathic ability. Exploratory factor analysis indicates a satisfactory structural validity, and the overall scale has a Cronbach's $\alpha$ of 0.80 [23]. The Chinese version also has acceptable psychometric properties [24]. In this study, the Cronbach's $\alpha$ of each subscale ranged from 0.60 to 0.82 .

Connor-Davidson Resilience Scale appraises the ability to deal with adversity. It is a 10-item instrument with an uni-dimensional structure. It is rated by a 5 -point Likert scale with lower scores indicating lower resilience. Exploratory factor analysis supports a one-factor construct and the Cronbach's $\alpha$ of the scale is 0.85 [25]. The Chinese scale also indicates an excellent internal consistency, test-retest reliability and structural validity [26]. The Cronbach's $\alpha$ of the scale in this study was 0.92 .

Simple Coping Style Questionnaire evaluates coping strategies to handle challenges under adversity. It is a 20-item instrument with 2 domains (adaptive coping and passive coping). The Chinese questionnaire is scored on a 4-point Likert scale, and each subscale is rated independently with higher scores indicating higher adaptive and passive coping. The Cronbach's $\alpha$ of the overall scale is 0.90 [27]. In this study, the Cronbach's $\alpha$ of each subscale ranged from 0.78 to 0.87 .

Professional Quality of Life Scale assesses positive and negative aspects of helping others who suffer from traumatic events. It comprises 30 items and 3 domains (CS, burnout and STS), with the latter 2 domains reflecting CF. The scale is rated by a 5 -point Likert scale, and each domain is ranked independently with higher scores indicating higher CS, burnout and STS. The score of each domain ranges from 10 to 50 and is classified into 3 levels (22 or less: low level, 23 to 41: average level, 42 or more: high level). Exploratory factor analysis supports a 3 -factor construct, and the Cronbach's $\alpha$ of each domain ranges from 0.72 to 0.87 [4]. The Chinese version also has satisfactory psychometric properties [28]. In this study, the Cronbach's $\alpha$ of each domain ranged from 0.78 to 0.91 . 


\section{Data collection}

Prior to the study, permission was obtained from each president of the selected hospitals. Then, one nurse with a Bachelor degree in nursing science from each hospital was selected as a research assistant to participate in a 2$\mathrm{h}$ online training session, which comprised the objectives of the study, the inclusion and exclusion criteria of the participants, and the process of data collection. The data was collected via an online survey, and a $Q R$ code was designated and distributed to each research assistant before the survey. The procedure of data collection was as follows: first, based on the inclusion and exclusion criteria, the research assistant in each hospital chose potential participants and introduced the aims of the study in a meeting room during day shift. Next, the potential participants were informed that participation was voluntary and anonymous, they were required to scan a designated QR code using their own smartphones, and an electronic written informed consent was required to be signed. Finally, the participants were instructed to complete and submit the online questionnaires. The study was conducted from Jul 1 to Aug 31, 2020.

\section{Statistical analysis}

SPSS 23.0 was used for data analysis. As each subscale of professional quality of life approximated normality, the differences in each subscale between subgroups were examined using independent samples t-tests or one-way analysis of variances. Pearson correlation analysis was used to explore the relationships between these variables. The effects of demographic factors, transition shock, empathy, resilience and coping strategies on each subscale of professional quality of life were examined using multiple regression analysis. $P<.05$ was statistically significant (two-tailed test).

\section{Ethical approval}

Ethical approval was obtained from the Human Subjects Ethics Sub-committee of West China Hospital of Sichuan University (no. 2020281). The informed consent was obtained from all of the subjects. The participants could participate in the study voluntarily and could withdraw when they wanted it at any time. All methods in this study were carried out in accordance with relevant guidelines and regulations.

\section{Results}

\section{Sample characteristics}

The respondents included 71 (18.1\%) men and 322 $(81.9 \%)$ women. The average age was 22.45 (standard deviation $=1.02$ ) ranging from 20 to 25 years. Over half of the respondents had a bachelor degree or above (65.1\%), and $58.3 \%$ of the respondents had siblings. Most of the respondents worked in a medical $(29.3 \%)$ or surgical unit
(24.7\%), and experienced patient death (69.0\%). Moreover, $30.3 \%$ of the respondents received empathy training (Table 1).

\section{The levels of professional quality of life}

The prevalence of average and high levels of CS were $80.2 \%$ (315 nurses) and 19.8\% (78 nurses). A total of 243 NGNs (61.8\%) reported low burnout, and 150 (38.2\%) reported average burnout. Moreover, the prevalence of low and average levels of STS were $42.5 \%$ (167 nurses) and $57.5 \%$ (226 nurses).

The mean scores of CS, burnout and STS were 37.86 $($ standard deviation $=5.16), 21.30$ (standard deviation $=$ 5.14) and 23.56 (standard deviation $=4.36$ ), respectively. NGNs with an associate degree or below reported significant higher CS, and significant lower burnout and STS than those with a bachelor degree or above. Compared to NGNs without empathy training, those receiving empathy training reported significant higher CS, and significant lower burnout and STS. Moreover, female nurses reported significant higher STS than male nurses, but no significant differences on CS and burnout were uncovered between female and male nurses. No significant differences on each subscale were found in NGNs with different units of assignment, with or without siblings, and with or without patient death experience (Table 1).

Relationships of transition shock, empathy, resilience and coping strategies with professional quality of life

Transition shock and passive coping had significant negative relationships with CS, and significant positive relationships with burnout and STS. Empathy, resilience and adaptive coping were significantly and positively related to CS, and significantly and negatively related to burnout and STS, respectively (Table 2).

Effects of demographic data, transition shock, empathy, resilience and coping strategies on professional quality of life

Based on the results of independent samples t-tests or one-way analysis of variances, significant demographic factors including sex, educational level and empathy training were incorporated into multiple regression analysis. The findings indicated that, transition shock, empathy, resilience and adaptive coping were significant contributors to CS, explaining $57.6 \%$ of the variance. Resilience was the strongest predictor $(\beta=.343, p<.001)$, followed by empathy $(\beta=.259, p<.001)$, transition shock $(\beta=-.192$, $p<.001)$ and adaptive coping $(\beta=.107, p<.05)$. Transition shock, empathy, resilience, and adaptive and passive coping were significant predictors for burnout, which explained $67.8 \%$ of the variance, with transition shock as the strongest contributor $(\beta=.430, p<.001)$, followed by resilience $(\beta=-.247, p<.001)$ and empathy $(\beta=-.189$, 
Table 1 Differences in each subscale of professional quality of life among subgroups $(n=393)$

\begin{tabular}{|c|c|c|c|c|}
\hline Variables & n (\%) & $\begin{array}{l}\text { CS } \\
\text { mean } \pm \text { standard deviation }\end{array}$ & $\begin{array}{l}\text { Burnout } \\
\text { mean } \pm \text { standard deviation }\end{array}$ & $\begin{array}{l}\text { STS } \\
\text { mean } \pm \text { standard deviation }\end{array}$ \\
\hline \multicolumn{5}{|l|}{ Sex } \\
\hline Male & $71(18.1)$ & $37.83 \pm 5.58$ & $20.77 \pm 5.22$ & $22.11 \pm 4.66$ \\
\hline Female & $322(81.9)$ & $37.87 \pm 5.07$ & $21.41 \pm 5.12$ & $23.51 \pm 4.26$ \\
\hline $\mathrm{t}(p)$ & & $-0.052(0.958)$ & $-0.948(0.344)$ & $-2.459(0.014)$ \\
\hline \multicolumn{5}{|l|}{ Educational level } \\
\hline Associate degree or below & $137(34.9)$ & $38.88 \pm 4.95$ & $19.93 \pm 4.88$ & $22.59 \pm 4.35$ \\
\hline Bachelor degree or above & $256(65.1)$ & $37.31 \pm 5.19$ & $22.03 \pm 5.13$ & $23.61 \pm 4.33$ \\
\hline $\mathrm{t}(p)$ & & $2.906(0.004)$ & $-3.918(0.000)$ & $-2.226(0.027)$ \\
\hline \multicolumn{5}{|l|}{ Having siblings } \\
\hline No & $164(41.7)$ & $37.73 \pm 5.74$ & $21.26 \pm 5.22$ & $23.20 \pm 4.23$ \\
\hline Yes & $229(58.3)$ & $37.95 \pm 4.70$ & $21.33 \pm 5.09$ & $23.30 \pm 4.45$ \\
\hline$t(p)$ & & $-0.417(0.677)$ & $-0.136(0.892)$ & $-0.214(0.830)$ \\
\hline \multicolumn{5}{|l|}{ Unit of assignment } \\
\hline Medical unit & $115(29.3)$ & $37.80 \pm 4.90$ & $21.17 \pm 4.96$ & $23.20 \pm 4.24$ \\
\hline Surgical unit & $97(24.7)$ & $38.30 \pm 5.78$ & $20.84 \pm 5.44$ & $22.87 \pm 4.19$ \\
\hline Emergence care unit & $14(3.6)$ & $37.79 \pm 5.62$ & $21.86 \pm 5.87$ & $23.29 \pm 5.37$ \\
\hline Intensive care unit & $33(8.4)$ & $37.48 \pm 4.56$ & $22.52 \pm 5.19$ & $24.03 \pm 4.48$ \\
\hline Operating unit & $63(16.0)$ & $37.10 \pm 5.22$ & $22.25 \pm 5.33$ & $24.19 \pm 4.63$ \\
\hline Other unit & $71(18.1)$ & $38.23 \pm 4.84$ & $20.61 \pm 4.57$ & $22.69 \pm 4.24$ \\
\hline$F(p)$ & & $0.525(0.758)$ & $1.273(0.275)$ & $1.188(0.314)$ \\
\hline \multicolumn{5}{|c|}{ Having experienced patient death } \\
\hline Yes & $271(69.0)$ & $37.84 \pm 5.35$ & $21.42 \pm 5.27$ & $23.38 \pm 4.38$ \\
\hline No & $122(31.0)$ & $37.91 \pm 4.72$ & $21.02 \pm 4.84$ & $22.98 \pm 4.32$ \\
\hline $\mathrm{t}(p)$ & & $-0.128(0.898)$ & $0.728(0.467)$ & $0.834(0.405)$ \\
\hline \multicolumn{5}{|l|}{ Empathy training } \\
\hline Yes & $162(30.3)$ & $38.78 \pm 5.06$ & $20.42 \pm 5.03$ & $22.81 \pm 4.39$ \\
\hline No & $231(69.7)$ & $37.22 \pm 5.14$ & $21.91 \pm 5.13$ & $23.57 \pm 4.32$ \\
\hline $\mathrm{t}(p)$ & & $2.985(0.003)$ & $-2.863(0.004)$ & $-1.688(0.042)$ \\
\hline
\end{tabular}

CS compassion satisfaction, STS secondary traumatic stress

Table 2 Relationships of transition shock, empathy, resilience and coping strategies with professional quality of life ( $n=393$ )

\begin{tabular}{|c|c|c|c|c|c|c|c|c|}
\hline Variables & TS & Empathy & Resilience & $A C$ & PC & CS & Burnout & STS \\
\hline TS & 1.000 & $-0.426^{* * *}$ & $-0.557^{* * *}$ & $-0.290^{* * *}$ & $0.356^{* * *}$ & $-0.556^{* * *}$ & $0.723^{* * *}$ & $0.631^{* * *}$ \\
\hline Empathy & & 1.000 & $0.600^{* * *}$ & $0.491 * * *$ & $-0.297^{* * *}$ & $0.618^{* * *}$ & $-0.593^{* * *}$ & $-0.370^{* * *}$ \\
\hline Resilience & & & 1.000 & $0.558^{* * *}$ & $-0.292^{* * *}$ & $0.689^{* * *}$ & $-0.684^{* * *}$ & $-0.428^{* * *}$ \\
\hline$A C$ & & & & 1.000 & 0.034 & $0.482^{* * *}$ & $-0.430^{* * *}$ & $-0.237^{* * *}$ \\
\hline$P C$ & & & & & 1.000 & $-0.294^{* * *}$ & $0.387^{* * *}$ & $0.362^{* * *}$ \\
\hline CS & & & & & & 1.000 & $-0.825^{* * *}$ & $-0.403^{* * *}$ \\
\hline Burnout & & & & & & & 1.000 & $0.669^{* * *}$ \\
\hline STS & & & & & & & & 1.000 \\
\hline
\end{tabular}

*** $P<0.001$. AC adaptive coping, CS compassion satisfaction, $P C$ passive coping, STS secondary traumatic stress, $T S$ transition shock 
$p<.001)$. NGNs with a bachelor degree or above reported significant higher burnout than those with an associate degree or below $(\beta=.080, p<.01)$. Moreover, transition shock, empathy and passive coping predicted STS significantly, explaining $42.0 \%$ of the variance. Transition shock was the strongest contributor $(\beta=.514, p<.001)$, followed by passive coping $(\beta=.149, p<.01)$ and empathy $(\beta=$ $-.100, p<.05)$ (Table 3).

\section{Discussion}

It was revealed that, higher transition shock contributed to less CS, and more burnout and STS, which indicated that NGNs who experienced more reality shock during the transition to clinical practice had lower CS and higher CF. The first year of clinical practice is an essential adjustment period for NGNs due to the lack of clinical competence [29]. The greatest reality-related shock NGNs perceived in the first year of job was the mismatch between actual and expected work and work environment [13]. Loss of social support, and incongruity in work and personal life were the greatest transition shock NGNs experienced in the first year of work [30]. Moreover, this study was conducted during the outbreak of the Covid-19 pandemic, in which in addition to shortages of personal protective equipment, inadequate staffing was one of the most pressing stressors experienced by nurses working in hospital settings, which negatively impacted nurse well-being [31]. Therefore, NGNs who enter nursing profession during the pandemic are likely to suffer from more reality shock in transition phase due to inadequate staffing and excessive workload. NGNs with more transition shock usually cannot effectively adapt to a real work environment and are susceptible to experience a variety of negative emotional states, less self-esteem and job involvement [32], which can result in increased CF and decreased CS. Accordingly, it is important to develop strategies (e.g., transition or preceptorship programmes) for facilitating the smooth transition and integration of NGNs, mitigating transition shock, hence promoting CS and reducing CF.

It was also revealed that, higher empathy significantly contributed to higher CS, and lower CF (burnout and STS) in NGNs, which are similar to the results of previous studies on experienced nurses [15, 16]. Empathy represents a caregiver's ability to understand and share in clients' thoughts and feelings from their perspectives, which can help identify clients' needs, provide needsbased care, and facilitate clients' satisfaction [33]. In turn, positive feedback from clients can assist in reducing nurse negative feelings driven by fear and workrelated trauma, and enhancing the pleasure from helping others. On the other hand, empathic care can reflect nurses' professional values, promote positive interactions between nurses and clients, and develop reciprocal trust within the therapeutic relationships, which can further facilitate CS and reduce CF in nurses including NGNs. Thus, based on our findings, it is essential to establish strategies of psychological formulation in increasing and sustaining empathy for NGNs.

Moreover, this study found that, resilience affected CS and burnout significantly, which are similar to the results of prior studies $[19,20]$. Resilience refers to an adaptive process when encountering with stressful events and adversity. Individuals with higher resilience usually do not regard workplace stressors as a threat, and are more capable of adopting problem-solving coping, avoiding emotion-centered coping, and seeking social support to handle workplace stressors, which can result in positive compassionate feelings towards others and low perception of burnout [4]. However, this study

Table 3 Effects of demographic data, transition shock, empathy, resilience and coping strategies on professional quality of life ( $n=$ 393)

\begin{tabular}{|c|c|c|c|c|c|c|c|c|c|}
\hline \multirow[t]{2}{*}{ Variables } & \multicolumn{3}{|l|}{ CS } & \multicolumn{3}{|c|}{ Burnout } & \multicolumn{3}{|l|}{ STS } \\
\hline & $\beta$ & $\mathrm{t}$ & $p$ & $\beta$ & $\mathrm{t}$ & $p$ & $\beta$ & $\mathbf{t}$ & $p$ \\
\hline Constant & - & 6.044 & 0.000 & - & 12.627 & 0.000 & - & 5.832 & 0.000 \\
\hline Sex (male/female) & - & - & - & - & - & - & 0.046 & 1.144 & 0.253 \\
\hline $\begin{array}{l}\text { Educational level (associate degree or } \\
\text { below/bachelor degree or above) }\end{array}$ & -0.063 & -1.865 & 0.063 & 0.080 & 2.722 & 0.007 & 0.001 & -0.008 & 0.994 \\
\hline Empathy training (yes/no) & -0.056 & -1.686 & 0.093 & 0.033 & 1.156 & 0.248 & 0.001 & 0.011 & 0.991 \\
\hline Transition shock & -0.192 & -4.647 & 0.000 & 0.430 & 11.915 & 0.000 & 0.514 & 10.574 & 0.000 \\
\hline Empathy & 0.259 & 5.914 & 0.000 & -0.189 & -4.952 & 0.000 & -0.100 & -2.311 & 0.021 \\
\hline Resilience & 0.343 & 6.947 & 0.000 & -0.247 & -5.732 & 0.000 & -0.024 & -0.411 & 0.681 \\
\hline Adaptive coping & 0.107 & 2.492 & 0.013 & -0.078 & -2.084 & 0.038 & -0.047 & -0.933 & 0.351 \\
\hline \multirow[t]{2}{*}{ Passive coping } & -0.041 & -1.098 & 0.273 & 0.098 & 2.999 & 0.003 & 0.149 & 3.393 & 0.001 \\
\hline & \multicolumn{3}{|c|}{$\begin{array}{l}\text { Adjusted } \mathrm{R}^{2}=0.576, \mathrm{~F}=77.196, \\
p<0.001\end{array}$} & \multicolumn{3}{|c|}{$\begin{array}{l}\text { Adjusted } \mathrm{R}^{2}=0.678, \mathrm{~F}=118.741, \\
p<0.001\end{array}$} & \multicolumn{3}{|c|}{$\begin{array}{l}\text { Adjusted } \mathrm{R}^{2}=0.420, \mathrm{~F}=36.445, \\
p<0.001\end{array}$} \\
\hline
\end{tabular}


did not support a significant effect of resilience on STS. The results are similar to the findings of a prior study on critical care nurses, which indicated that although resilience, as a predictor, significantly explained $15.4 \%$ of the variance of STS, its explaining effect on STS was lower than those on CS (66.0\%) and burnout (22.0\%) [20]. The results in our study suggest that, strategies for facilitating resilience training in NGNs are necessary in future studies to facilitate CS and alleviate burnout.

In parallel to the findings of prior studies [17, 21], it was revealed that, passive coping in NGNs was a significant contributor to CF, but it did not significantly predict CS. Coping is a process of fitting into the ward culture, and NGNs who adopt passive coping are susceptible to have low self-efficacy and be lack of confidence in dealing with stressful events, which may affect their ability to work with clients who suffer from stressful events and result in more CF. In this study, it was also revealed that, adaptive coping significantly contributed to CS, which is similar to the results of prior studies [21, 34]. Nurses with adaptive coping strategies usually search for social support and effective solutions when facing workplace stressors, and higher problemsolving coping significantly contributes to higher CS [21]. Therefore, it is pivotal to develop coping training programmes for NGNs, which focus on promoting adaptive coping and avoiding passive coping, in order to further enhance $\mathrm{CS}$ and reduce $\mathrm{CF}$.

In addition, this study revealed that, NGNs with a bachelor degree or above reported higher burnout than those with an associate degree or below, but no significant differences on STS and CS were discovered between NGNs with different educational levels. The results are not similar to the findings of prior studies on experienced nurses, which indicated that educational level was not a significant predictor for each subscale of professional quality of life in cancer nurses or critical care nurses $[17,35]$. Burnout refers to negative feelings of frustration and exhaustion due to difficulties in handling job-related stressors effectively [4]. In China, compared to NGNs with an associate degree or below, those with a bachelor degree or above usually receive more training on theoretical knowledge and critical thinking, and less training on clinical skills during school education, which may result in more frustration and hopelessness because of difficulties in coping with workplace stressors in the early phase of career development when clinical skills are highlighted.

\section{Limitations}

Three limitations were noted. First, a cross-sectional design was used, which could not explore the causal mechanisms between the variables. Second, the samples were only selected from tertiary hospitals in Sichuan province, without samples from secondary and primary institutes, which might limit generalizability of the results. Finally, although the impact of transition shock, empathy, resilience and coping strategies on professional quality of life were examined, the reciprocal associations between the predictors (e.g., moderating or mediating effects) were not explored.

\section{Conclusion}

This study indicates that, higher transition shock and lower empathy result in less CS and more burnout and STS. Higher adaptive coping and resilience cause higher CS and lower burnout. The results of our study offer a new insight for nursing managers in clinical settings to develop effective strategies to promote professional quality of life in NGNs. Strategies such as transition or preceptorship programmes, and empathy, resilience and coping training are effective methods to reduce transition shock, facilitate empathy, resilience and coping, and consequently, enhance professional quality of life in NGNs.

\section{Abbreviations}

AC: Adaptive Coping; CS: Compassion Satisfaction; CF: Compassion Fatigue; NGN: Newly Graduated Nurses; PC: Passive Coping; STS: Secondary Traumatic Stress; TS: Transition Shock

\section{Acknowledgements \\ The authors thanks all of the newly graduated nurses who participated in this study.}

\section{Authors' contributions}

$X-Y . C_{.,}$J. L., and S. G. contributed to the conception and design of the study $X-Y$. C., J. L., and S. G. conducted the data collection and analyses, and wrote the article. All authors have read and approve the final manuscript.

\section{Funding}

This research did not receive any specific grant funding from agencies in the public, commercial, or not-for-profit sectors.

\section{Availability of data and materials}

The datasets generated and/or analysed during the present study are not publicly available due to the data being proprietary and confidential records of the West China Hospital/West China School of Nursing, Sichuan University, but are available from the corresponding author on reasonable request.

\section{Declarations}

\section{Consent to publication}

The author(s) declare that they consent to publication.

Ethics approval and consent to participate Ethical approval was obtained from the Human Subjects Ethics Subcommittee of West China Hospital of Sichuan University (no. 2020281). The informed consent was obtained from all of the subjects. The participants could participate in the study voluntarily and could withdraw when they wanted it at any time. All methods in this study were carried out in accordance with relevant guidelines and regulations.

Competing interests

The author(s) declare that they have no competing interests. 
Received: 17 February 2021 Accepted: 19 April 2021

Published online: 23 April 2021

\section{References}

1. World Health Organization. Available at: https://www.who.int/hrh/resources/ global_strategy_workforce2030_14_print.pdf?ua=1. Accessed 15 Jun 2017.

2. National Health Commission of the People's Republic of China. Statistical Bulletin of China's Health Care Development in 2018. Available at: http:// www.nhc.gov.cn/guihuaxxs/s10748/201905/9b8d52727cf346049de8acce2 5ffcbd0.shtml. Accessed 22 May 2019.

3. OECD. Nurses (indicator). Available at: https://data.oecd.org/healthres/nurses. htm. Accessed 28 Oct 2020.

4. Stamm B. The Concise PRoQOL Manual. Pocatello, ID: ProQOL. org. Available at: www.proqol.org/uploads/ProQOL_Concise_2ndEd_12-2010.pdf. 2010.

5. Sinclair S, Raffin-Bouchal S, Venturato L, Mijovic-Kondejewski J, SmithMacDonald L. Compassion fatigue: a meta-narrative review of the healthcare literature. Int J Nurs Stud. 2017;69:9-24. https://doi.org/10.1016/j. ijnurstu.2017.01.003.

6. Hegney DG, Craigie M, Hemsworth D, Osseiran-Moisson R, Aoun S, Francis $K$, et al. Compassion satisfaction, compassion fatigue, anxiety, depression and stress in registered nurses in Australia: study 1 results. J Nurs Manag. 2014;22(4):506-18. https://doi.org/10.1111/jonm.12160.

7. Pang $Y$, Dan $H$, Jung $H$, Bae N, Kim O. Depressive symptoms, professional quality of life and turnover intention in Korean nurses. Int Nurs Rev. 2020; 67(3):387-94. https://doi.org/10.1111/inr.12600.

8. Cao T, Huang X, Wang L, Li B, Dong $X$, Lu H, et al. Effects of organisational justice, work engagement and nurses' perception of care quality on turnover intention among newly licensed registered nurses: a structural equation modelling approach. J Clin Nurs. 2020;29(13-14):2626-37. https:// doi.org/10.1111/jocn.15285.

9. Cavanagh N, Cockett G, Heinrich C, Doig L, Fiest K, Guichon JR, et al. Compassion fatigue in healthcare providers: a systematic review and metaanalysis. Nurs Ethics. 2020;27(3):639-65. https://doi.org/10.1177/096973301 9889400.

10. Hunsaker S, Chen HC, Maughan D, Heaston S. Factors that influence the development of compassion fatigue, burnout, and compassion satisfaction in emergency department nurses. J Nurs Scholarsh. 2015;47(2):186-94. https://doi.org/10.1111/jnu.12122.

11. Kim K, Han Y, Kim JS. Korean nurses' ethical dilemmas, professional values and professional quality of life. Nurs Ethics. 2015;22(4):467-78. https://doi. org/10.1177/0969733014538892.

12. Duchscher JE. Transition shock: the initial stage of role adaptation for newly graduated registered nurses. J Adv Nurs. 2009;65(5):1103-13. https://doi. org/10.1111/j.1365-2648.2008.04898.x.

13. Labrague LJ, De Los Santos JAA. Transition shock and newly graduated nurses' job outcomes and select patient outcomes: a cross-sectional study. J Nurs Manag. 2020;28(5):1070-9. https://doi.org/10.1111/jonm.13033.

14. Figley C. Compassion fatigue: psychotherapists' chronic lack of self care. J Clin Psychol. 2002;58(11):1433-41. https://doi.org/10.1002/jclp.10090.

15. Duarte J, Pinto-Gouveia J, Cruz B. Relationships between nurses' empathy, self-compassion and dimensions of professional quality of life: a crosssectional study. Int J Nurs Stud. 2016;60:1-11. https://doi.org/10.1016/j. ijnurstu.2016.02.015.

16. Hui Z, Dai $X$, Wang $X$. Mediating effects of empathy on the association between nursing professional values and professional quality of life in Chinese female nurses: a cross-sectional survey. Nurs Open. 2019;7(1):411-8. https://doi.org/10.1002/nop2.404.

17. Yu H, Jiang A, Shen J. Prevalence and predictors of compassion fatigue, burnout and compassion satisfaction among oncology nurses: a crosssectional survey. Int J Nurs Stud. 2016;57:28-38. https://doi.org/10.1016/j. ijnurstu.2016.01.012.

18. Walpita YN, Arambepola C. High resilience leads to better work performance in nurses: evidence from South Asia. J Nurs Manag. 2020;28(2): 342-50. https://doi.org/10.1111/jonm.12930.

19. Hegney DG, Rees CS, Eley R, Osseiran-Moisson R, Francis K. The contribution of individual psychological resilience in determining the professional quality of life of Australian nurses. Front Psychol. 2015;6:1613.

20. Alharbi J, Jackson D, Usher K. Personal characteristics, coping strategies, and resilience impact on compassion fatigue in critical care nurses: a crosssectional study. Nurs Health Sci. 2020;22(1):20-7. https://doi.org/10.1111/ nhs. 12650.
21. Al Barmawi MA, Subih M, Salameh O, Sayyah Yousef Sayyah N, Shoqirat N, Abdel-Azeez Eid Abu Jebbeh R. Coping strategies as moderating factors to compassion fatigue among critical care nurses. Brain Behav. 2019;9(4): e01264.

22. Xue YR, Lin P, Gao XQ, Zhao ZJ, Li L, Liu GJ, et al. Development and the reliability and validity test of the transition shock of newly graduated nurses scale. Chin J Nurs. 2015;50(6):674-8 (in Chinese).

23. Hojat M, Gonnella JS, Nasca TJ, Mangione S, Vergare M, Magee M. Physician empathy: definition, components, measurement, and relationship to gender and specialty. Am J Psychiatry. 2002;159(9):1563-9. https://doi.org/10.1176/a ppi.ajp.159.9.1563.

24. An XQ. Study on Chinese version of the Jefferson scale of empathy-health professionals (JSE-HP) in nurses. Shanxi: Shanxi Medical University; 2009. (in Chinese)

25. Campbell-Sills L, Stein MB. Psychometric analysis and refinement of the Connor-Davidson resilience scale (CDRISC): validation of a 10-item measure of resilience. J Trauma Stress. 2007;20(6):1019-28. https://doi.org/10.1002/ jts.20271.

26. Wang L, Shi Z, Zhang Y, Zhang Z. Psychometric properties of the 10-item Connor-Davidson resilience scale in Chinese earthquake victims. Psychiatry Clin Neurosci. 2010;64(5):499-504. https://doi.org/10.1111/j.1440-1819.2010. 02130.x.

27. Wang XD, Wang $X L, M a H$. The handbook of psychological scale. revised ed. Beijing: Chinese Mental Health Journal Press; 1999. (in Chinese)

28. Wu JM, Zhang YQ, Yang Y, Xu Y. Evaluation of reliability and validity of Chinese version of professional quality of life scale for nurses. J Shanghai Jiaotong University (Medical Science). 2014;34(9):1281-5 (in Chinese).

29. Woo MWJ, Newman SA. The experience of transition from nursing students to newly graduated registered nurses in Singapore. Int J Nurs Sci. 2019;7(1): 81-90. https://doi.org/10.1016/j.jijnss.2019.11.002.

30. Kim EY, Yeo JH. Transition shock and job satisfaction changes among newly graduated nurses in their first year of work: a prospective longitudinal study. J Nurs Manag. 2020;29(3):451-8. https://doi.org/10.1111/jonm.13164.

31. American Nurses Association, 2020. COVID-19 survey March 20-April 10. Available at: https://www.nursingworld.org/practice-policy/workenvironment/health-safety/disasterpreparedness/coronavirus/what-youneed-to-know/covid-19-survey-results/

32. Nour V, Williams AM. "theory becoming alive": the learning transition process of newly graduated nurses in Canada. Can J Nurs Res. 2019;51(1):613. https://doi.org/10.1177/0844562118771832.

33. Moghaddasian S, Lak Dizaji S, Mahmoudi M. Nurses empathy and family needs in the intensive care units. J Caring Sci. 2013;2(3):197-201. https://doi. org/10.5681/jcs.2013.024.

34. Potter $P$, Deshields $T$, Rodriguez $S$. Developing a systemic program for compassion fatigue. Nurs Adm Q. 2013;37(4):326-32. https://doi.org/10.1 097/NAQ.0b013e3182a2f9dd.

35. Sacco TL, Ciurzynski SM, Harvey ME, Ingersoll GL. Compassion satisfaction and compassion fatigue among critical care nurses. Crit Care Nurse. 2015; 35(4):32-43. https://doi.org/10.4037/ccn2015392.

\section{Publisher's Note}

Springer Nature remains neutral with regard to jurisdictional claims in published maps and institutional affiliations.

Ready to submit your research? Choose BMC and benefit from:

- fast, convenient online submission

- thorough peer review by experienced researchers in your field

- rapid publication on acceptance

- support for research data, including large and complex data types

- gold Open Access which fosters wider collaboration and increased citations

- maximum visibility for your research: over $100 \mathrm{M}$ website views per year

At BMC, research is always in progress.

Learn more biomedcentral.com/submissions 